\title{
Realidades de la Amazonía Colombiana: Territorio, Conflicto Armado y Riesgo Socioecológico
}

\author{
Realities of the Colombian Amazon: Territory, Armed Conflict And \\ Socio-Ecological Risk
}

\section{Hernán Felipe Trujillo Quintero}

Universidad San Buenaventura, Colombia

htrujillo@usbbog.edu.co

Resumen: El artículo tiene como objetivo vislumbrar las realidades político-ecológicas del territorio amazónico colombiano, a partir de una investigación explicativa, con el propósito de develar las dinámicas poblacionales, la inferioridad que se ha gestado en las relaciones de poder (centro-periferia) con la ausencia del Estado y sus consecuencias en la relación ser humano-naturaleza. Por lo tanto, se concluye que hay un riesgo socioambiental por la falta de poder nacional sobre el territorio, especialmente, por la persistencia de cultivos ilícitos.

Palabras clave: Amazonía colombiana, conflicto armado, conservación, territorio.

Abstract The objective of this paper is to show the ecological and political realities of the Colombian Amazon as part of an explanatory research, with the purpose of revealing the population dynamics, the inferiority that has developed within power relationships (center-periphery) due to the absence of State control, and the consequences in the mannature relationship. It is therefore concluded that there is a socio-environmental risk due to the lack of national control over its territory, particularly due to persisting illegal crops.

Keywords: Colombian Amazon, armed conflict, conservation, territory.

Fecha de recepción: 02-09-13 Fecha de reenvíos: 04-02-14 / 11-02-14 / 25-02-14 / 03-03-14 /

10-03-14 / 24-04-14 / 25-04-14 / 02-06-14 / 10-06-14 Fecha de aceptados: 12-06-14

Fecha de publicación 26-06-14

http://dx.doi.org/10.15359/abra.34-48.4

Hernán Felipe Trujillo Quintero

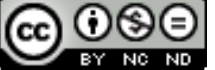


La participación de Colombia dentro del total de la Amazonía es proporcionalmente baja, tan solo posee el $6,4 \%$; pero la participación de la Amazonía dentro del territorio nacional es muy elevada, $41,8 \%$. A pesar de lo anterior, estos ecosistemas colombianos enfrentan diversas tensiones sociales y políticas que afectan su estabilidad y equilibrio, lo que se expresa en un desconocimiento y un descuido sistemático de la región más extensa del país. Este artículo tiene como objetivo vislumbrar las realidades político-ecológicas del territorio amazónico colombiano, a partir de una investigación explicativa, con el propósito de develar la inferioridad que se ha gestado en las relaciones de poder (centroperiferia) y sus consecuencias en la relación ser humano naturaleza. Consta de dos partes: la primera aborda la dinámica del territorio y poblamiento en las zonas de la Amazonía colombiana, en un contexto histórico; y la segunda desarrolla las tensiones existentes entre el Estado y grupos armados ilegales, y su injerencia con el conflicto armado ilegal y la permanencia de los equilibrios ecosistémicos.

\section{Territorio y colonización de la Amazonía colombiana.}

\section{Primera oleada migratoria. Llegan los españoles.}

Los procesos de poblamiento y colonización de los territorios en Colombia obedecieron a lógicas de depredación -con excepción de las culturas indígenas precolombinas-, y con diferentes ciclos migratorios. El primero de ellos se remonta a la época prehispánica, al finalizar la última era glacial, hace aproximadamente unos 9.000 años. Asimismo se cree que la ocupación habría llegado por el oriente andino por medio de la familia de los Arawac, provenientes de Centroamérica; y que la interacción de los indígenas con los españoles se habría dado entre 1536 y 1560, cuando llegaron al territorio amazónico algunas expediciones atraídas por la leyenda del dorado que permitieron la colonización en los Andes y la navegación de algunos ríos que recorren sus altiplanicies hasta la desembocadura del río Amazonas (Cepal y Patrimonio Natural, 2013 , p. 19), especialmente las realizadas por los expedicionarios Pizarro y Orellana, entre los años 1541 y 1542, quienes encontraron asentamientos indígenas en donde se desarrollaron la explotación del oro y cultivos de algodón (Reis, 1989, p. 62).

Para fines del siglo XVI la explotación de oro en la Amazonía desciende vertiginosamente, incluso en las zonas de explotación en los actuales 
territorios de Vaupés, Amazonas y Putumayo y, ante la falta de recursos para la supervivencia, se producen rebeliones indígenas que terminaron con la destrucción de los asentamientos españoles. En vista de los desmanes, para 1573 la Corona Española prohíbe nuevas expediciones hacia el oriente del virreinato, de tal manera que deja la colonización en manos de los misioneros religiosos entre el siglo XVI y XVII (Chantré, 1901, p.12; Cepal y Patrimonio Natural, 2013, p. 21).

La colonización, sin embargo, expuso a los indígenas amazónicos a nuevas enfermedades traídas del viejo mundo y junto con la esclavización y la explotación dejó como secuela una disminución significativa de población nativa, lo cual obligó a algunos sobrevivientes a migrar hacia territorios más orientales de los ríos Caquetá, Putumayo y Amazonas (Cepal y Patrimonio Natural, 2013, p. 21).

\section{Segunda oleada migratoria. Auge de recursos naturales.}

El país sufrió un gran retroceso debido a la expulsión de los jesuitas en 1767 y a la quiebra de las misiones franciscanas a fines del siglo XVIII. Solo hasta después de la mitad del siglo XIX, con la expedición de la Comisión Corográfica Nacional, se consolidaron algunos conocimientos geográficos del oriente de la Nueva Granada, que ayudaron a dimensionar su tamaño (Chantré, 1901, pp. 55-56).

El siglo XX aparece con oportunidades de comercio de recursos naturales, lo que motivó la llegada de colonos provenientes de las partes altas de las montañas andinas y del sur de la Amazonía, especialmente de países como Perú y Ecuador. De tal manera que se inicia con la extracción de quina en los años 1870 alrededor de las cuencas de los ríos del Caquetá Putumayo, y se convertiría en el principal producto de exportación colombiano entre 1881 y 1883 (Mora, 2006, p. 4).

Luego de la crisis de la quina, que llevó a la quiebra de empresas comerciales y el decaimiento de sus zonas de explotación, las actividades económicas se volcaron al auge cauchero. Los colonos provenientes del interior del país y del Perú capturaron y esclavizaron a los pueblos indígenas Uitotos, Caraguayes, Macaguajes e Inganos, para que recogieran el látex del árbol ${ }^{1}$ de caucho y establece puertos de recolección en los ríos Caquetá, Putumayo y Amazonas (Cepal y

1 Especie vegetal nativa de los bosques amazónicos 
Patrimonio Natural, 2013, p. 22). La introducción de la navegación de vapor en 1853 potenció el comercio del caucho por las arterias fluviales de la Amazonía, y tuvo consecuencias negativas en la dinámica poblacional indígena con respecto a los malos tratos y la ausencia de condiciones laborales (Mora, 2006, pp. 171-180). Luego de las bonanzas, el auge aurífero incentivó la llegada de colonos provenientes del Cauca, quienes aprovecharon el cauce de los ríos Caquetá, Putumayo y Caguán para su extracción, trayendo consigo afrodescendientes para trabajos rudos. Este auge estuvo acompañado de las misiones capuchinas que abrieron los primeros caminos al territorio desde la cordillera oriental (Chantré, 1901).

\section{Tercera y cuarta oleada. Política y conflicto armado.}

La guerra con Perú, auspiciada por la Casa Arana con la intención de ampliar sus extensiones en los territorios colombianos para la explotación de caucho, motivó uno de los primeros sentimientos nacionalistas del siglo $\mathrm{XX}$ en los colombianos. Varias personas provenientes de los actuales departamentos de Cundinamarca, Antioquia, Huila y Tolima hicieron parte del pie de fuerza para esta guerra que solo dejó un muerto. Muchos de los que migraron a la Amazonía se instalaron en los territorios anexos a los ríos Caquetá, Putumayo y Amazonas (Pineda, 1993, p. 140). En la década de los cincuenta, la llegada de colonos provenientes de los actuales departamentos del Huila y Tolima, quienes huían de la violencia política que se vivía en las montañas andinas, y quienes también aprovecharon el auge maderero que empezaba en la región (Molano, 1987, p. 98), explican la tercera oleada.

Por último, hacia la década de los ochenta, el auge cocalero motivó a personas provenientes del Huila, Cauca y de la Costa Pacífica, quienes aprovecharon terrenos baldíos y selváticos para arrasarlos y dar paso a los cultivos ilícitos (Molano, 1984, pp. 110-115). Lo anterior explica la cuarta oleada migratoria hacia territorios Amazónicos, y nos vamos a ocupar de esta en las siguientes líneas.

\section{Población amazónica en cifras.}

Con respecto a la población que habita los territorios amazónicos colombianos, las estadísticas recogidas a lo largo del siglo XX por autoridades gubernamentales señalan que los pobladores de la región Amazónica desde comienzos de siglo XX hasta el 2010 se multiplicaron 
por 20, en donde se pasa de 50.783 en la década de los treinta, a 1.029.002 en el 2010. La población nacional en el mismo periodo solo se multiplicó por 6 . La proporción de los habitantes de la Amazonía en la población nacional pasó de representar menos del 0,5\% a comienzos del siglo XX, a más del 2,2\% en el 2011 (Departamento Administrativo Nacional de Estadística, 2012).

Hay una tendencia de crecimiento en la participación de la población de los departamentos de la Amazonía en el total de la población colombiana, aunque en los últimos 17 años se ha estabilizado (véase Gráfico 1). Esto último puede explicarse, como bien lo señala Murad (2003), por el conflicto armado que han vivido estos departamentos, y que ha obligado a desplazarse a un buen número de población; pero debido a que la tasa de natalidad en la región es superior a la media nacional, ha compensado el efecto de la violencia, lo que anuló su incidencia en lo que demografía se refiere.

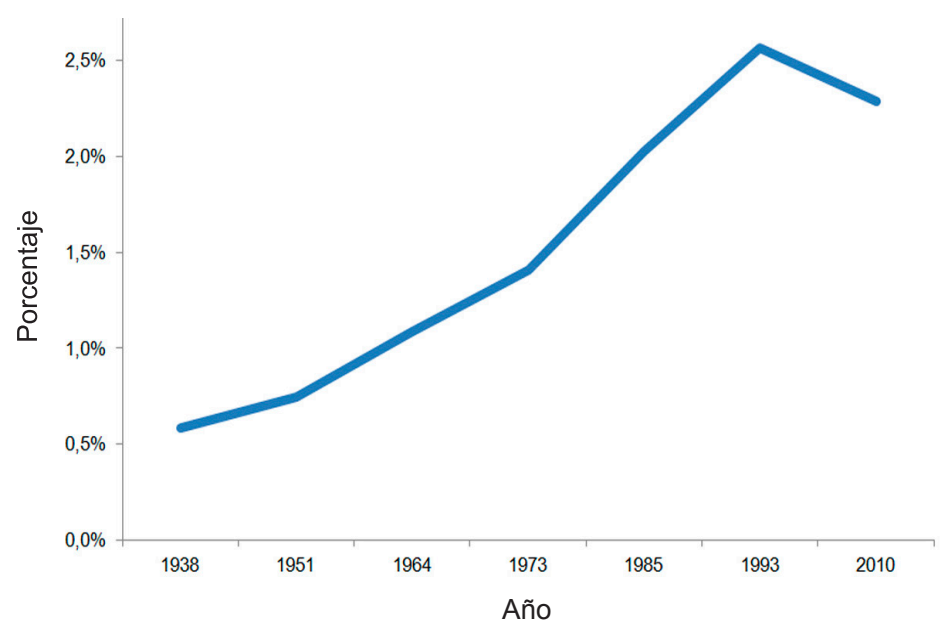

Figura 1. Participación de la población amazónica en el total nacional. Fuente: Elaboración propia. Datos obtenidos del DANE (2012).

Todos los Departamentos que pertenecen a la región amazónica tienen tasas de crecimiento demográfico por encima de la media nacional y se cree que la participación de la región en el censo poblacional seguirá en aumento por la bonanza de hidrocarburos y minerales que traerá más población a sus territorios en los próximos años. Si bien no hay una cifra confiable que dé cuenta de estas dinámicas, el gran dinamismo de los sectores económicos en estos territorios amazónicos podrá representar para el 2020 el 4\% del total de la población nacional, con más de 3 millones de habitantes (Trujillo, 2011, p. 15). 
Los indígenas de la región Amazónica representan el 6,7\% del total de la población indígena de Colombia, siendo el departamento de Putumayo el que concentra cerca de la mitad del total de indígenas de la región. Al analizar la distribución de la población Amazónica se observa que el $13,08 \%$ es indígena, pues de los 717.577 habitantes de los departamentos de Amazonas, Caquetá, Guainía, Guaviare, Putumayo y Vaupés, 93.840 son indígenas (véase Tabla 1). A diferencia del registro nacional, en el que solo el $3 \%$ de la población es indígena, en la Amazonía este grupo étnico posee una importancia más amplia que en la demás regiones colombianas.

Tabla 1.

Población indígena por departamento y total nacional.

\begin{tabular}{cccc}
\hline Departamento & Total & $\begin{array}{c}\text { Participación } \\
\text { sobre el } \\
\text { subtotal } \\
\text { Amazonía }\end{array}$ & $\begin{array}{c}\text { Participación } \\
\text { sobre el total } \\
\text { Nacional }\end{array}$ \\
\hline Amazonas & 19.000 & $20,2 \%$ & $1,4 \%$ \\
Caquetá & 5.026 & $5,4 \%$ & $0,4 \%$ \\
Guainía & 11.595 & $12,4 \%$ & $0,8 \%$ \\
Guaviare & 2.117 & $2,3 \%$ & $0,2 \%$ \\
Vaupés & 11.587 & $12,3 \%$ & $0,8 \%$ \\
Putumayo & 44.515 & $47,4 \%$ & $3,2 \%$ \\
Subtotal & 93.840 & $100,0 \%$ & $6,7 \%$ \\
Amazonía & & & $100,0 \%$ \\
Total Nacional & 1.392 .623 & - & \\
\hline
\end{tabular}

Nota: Fuente: Elaboración propia. Datos obtenidos del DNP (2010).

La distribución de la población contrasta con lo que ocurre en el resto del país, debido a que cerca de la mitad de las personas viven en áreas urbanas, mientras que el dato nacional es superior al $75 \%$ (Departamento Administrativo Nacional de Estadística, 2012) . Los cambios de lo rural hacia lo urbano deben tenerse en cuenta para precisar la velocidad de crecimiento de estas formas de poblamiento y, en particular, el tipo de actividades que se desarrollan allí, con el fin de precisar si resultan 
compatibles o no con las funciones ambientales de los restos rurales en el territorio. Para Alisos (2011, pp. 22-24), dado el auge minero-energético que experimenta la región, es posible esperar una transformación sustancial de los indicadores de crecimiento y densidad poblacional.

\section{Tensión entre el Estado y los grupos armados ilegales en la Amazonía colombiana.}

\section{Ausencia del Estado y aparición de las FARC.}

La presencia de grupos armados ilegales y de narcotráfico ${ }^{2}$ en la región forma parte de la historia reciente de la Amazonía colombiana, pero viene marcando pautas importantes en materia de conservación de ecosistemas, poblamiento y captura de rentas. Las razones de la consolidación de estos fenómenos son variadas y dependen de la lógica con la que se le mire; sin embargo, se puede encontrar una verticalidad entre las relaciones de poder que ha ejercido el Estado colombiano sobre este territorio, la consolidación de mercados locales claramente definidos, la estrategia militar y la financiación de los grupos armados ilegales que operan allí.

Asimismo, debemos empezar por reconocer que, históricamente, los departamentos que hoy forman parte de esta región del país fueron territorios olvidados por el Estado colombiano. Desde la Constitución de la Gran Colombia, los territorios han sido anexados sin ningún criterio administrativo o de ejercicio de soberanía claramente establecido ${ }^{3}$. Así, la competencia administrativa, el poder político y judicial era ejercido por los regiones encumbrados en las montañas andinas, quienes evidentemente desconocían las dinámicas de aquellos selvas.

A partir de la Constitución de 1886, el ejercicio de soberanía del Estado colombiano, constituido en forma de república unitaria, concentró el poder y privilegió un régimen de mayorías y olvida los territorios sin mucha densidad poblacional. Los denominados Territorios Nacionales

\footnotetext{
2 Por narcotráfico entendemos las actividades ilícitas relacionadas con sustancias psicoactivas como la cocaína, amapola y marihuana; y cuyo accionar se dirige a la producción, transformación, transporte, distribución y consumo.

3 El área que hoy forma parte de la región de la Amazonía colombiana pasó de pertenecer de la Provincia de Popayán (1810-1824), a los Departamentos de Boyacá y Azuay (1824-1852), al Territorio del Caquetá (1852-1863), al Estado de Cauca (1863-1886), y a ser considerados Territorios Nacionales cuya competencia en funciones administrativas estaba bajo la tutela del departamento del Cauca (1886-1991).
} 
aludían a regiones aisladas, con baja densidad poblacional y con comunidades indígenas; por tal razón, la Constitución de ese año no quiso ocuparse de ellos y delegó al Congreso Nacional para que definiera sus competencias como mejor le pareciera. Su jurisdicción y autonomía, por tanto, quedaban fuera de la Constitución.

Tal era la desidia del Estado por estos territorios, que Kalmanovitz \& López (2000, p. 24) señala que en 1905 el gobierno nacional de Rafael Reyes entregó en los actuales departamentos del Caquetá y Amazonas una concesión de tierras selváticas a Fidel Cano Cuellar, quien organizó en Estados Unidos una sociedad de capital denominada Amazon Colombian Rubber and Trading Company, además fue quien le ofreció a la Casa Arana comprar las propiedades que tenía en estos territorios para que pudiera explotar caucho. Sin embargo, la Casa Arana se negó a vender sus propiedades y la compañía quebró debido a que la falta de presencia militar y política en la zona no era capaz de asegurar las inversiones. Como bien lo señala Sanguino y Valencia (2005), estos territorios eran la representación de la ausencia del Estado, eran territorios de nadie, y la relación que los escasos pobladores tuvieron con el Estado estuvo mediada por el clientelismo y las viejas prácticas políticas o simplemente fue una relación de ocupación.

Así, la conformación de las Intendencias para que custodiaran administrativamente el vasto territorio despoblado del Amazonas, pero cuyas principales funciones administrativas y judiciales seguirían en cabeza del Estado central, sirvieron de base para la expedición de la Ley 2 de 1959, en donde quedaron definidos estos territorios como Reserva Forestal para la desarrollo de la economía forestal y protección de los suelos, las aguas y la vida silvestre ${ }^{4}$.

Quedaba por fuera del conocimiento del Estado todo aquello que allí se gestaba, como los procesos sociales y las relaciones de poder entre los escasos habitantes que ocupaban la Amazonía desde épocas

4 La ley de Reserva Forestal dividió el territorio en siete zonas. Específicamente, la Zona de Reserva Forestal de la Amazonía, quedó comprendida dentro de los siguientes límites generales: "Partiendo de Santa Rosa de Sucumbíos, en la frontera con el Ecuador, rumbo noreste, hasta el cerro más alto de los Picos de la Fragua; de allí siguiendo una línea, 20 kilómetros al oeste de la Cordillera Oriental hasta el Alto de Las Oseras; de allí en línea recta, por su distancia más corta, al Río Ariari, y por este hasta su confluencia con el Río Guayabero o el Guaviare, por el cual se sigue aguas abajo hasta su desembocadura en el Orinoco; luego se sigue la frontera con Venezuela y el Brasil, hasta encontrar el Río Amazonas, siguiendo la frontera sur del país, hasta el punto de partida". Ley 2 de 1959. Artículo 1, numeral g. 
prehispánicas. Las razones del olvido por parte del Estado responden, entonces, a la baja densidad poblacional de la región, a una falta de interés político, y en consecuencia, una ruptura en la comunicación entre el interior del país y la Amazonía, en donde se destaca la ausencia de carreteras e infraestructura de transporte (Jaramillo, Mora \& Cubides, 1989).

Todas las anteriores razones sirvieron para que el conflicto armado, que inició después de la segunda mitad del siglo XX, consolidara las estructuras militares subversivas en estos territorios. Las razones de la toma de poder de estas estructuras armadas ilegales en la Amazonía, además de la ausencia del Estado en la región, han sido abordadas por Molano (1980; 1984; 1987; 1994; 2002), León Gómez (1988; 1991; 1996), Pécaut (1997) y Jaramillo et al. (1989), quienes señalan que estos territorios son aptos para el cultivo de hoja de coca debido a la extensión geográfica, a la orografía y a las características socioeconómicas de la población, mayoritariamente en condición de pobreza. Asimismo, en cuanto a la estrategia militar, eran territorios desconocidos por el Ejército colombiano, lo que otorgaba ventajas importantes de ataque y repliegue, además, por supuesto, de una fácil dominación por la ausencia de soberanía estatal en la zona.

De esta manera, las Fuerzas Armadas Revolucionarias de Colombia (FARC), en su Quinta Conferencia celebrada entre los años 1966 y 1974, definen como núcleo de expansión las zonas del río Caguán y Caquetá ubicados en los departamentos de Caquetá y Putumayo, con el objetivo de conquistar territorios con baja presencia estatal y con conflictos rurales no resueltos (Vélez, 2001, pp.156-157). Por aquella época, el grupo guerrillero se encontraba consolidando sus estructuras militares, y aún no eran protagonistas a nivel nacional, solo ejercían liderazgos locales (Rangel, 1999). Pero luego de la celebración de la Séptima Conferencia en 1982, las FARC replantean su accionar militar y su lucha armada contra el Estado colombiano. Su fuente de financiación principal empieza a volcarse hacia el narcotráfico, y se proponen tres fases que incluyen, a saber: i) crecimiento organizacional como principal objetivo, ii) montar un cerco subversivo a la capital del país, y iii) el establecimiento de un gobierno provisional en las selvas del sur del país (Vélez, 2001, pp. 162-164). Si bien no lograron ninguno de los objetivos al finalizar la década de los ochenta, la expansión hacia el sur del país ayudó a consolidar las estructuras guerrilleras en los departamentos de Caquetá, Putumayo y Amazonas. Para ese entonces, las FARC ya 
tenían un protagonismo nacional muy fuerte por su escalada de violencia y se mantenían en permanente interlocución con el gobierno colombiano --vías diplomáticas y de hecho--.

La presencia en estos territorios para las FARC significó un motor importante para su expansión, pues además de consolidar su vínculo con la población civil, los cultivos ilícitos allí sembrados sirvieron para financiar gran parte de sus estructuras, lo que garantizaría su crecimiento en la década de los noventa (Rangel, 1999). Es así como desde 1985 las FARC empiezan un proceso de expansión en las zonas ganaderas del Caquetá, en las zonas petroleras del Putumayo y en las áreas fronterizas de Putumayo y Amazonas (Echandía, 1999, p. 4). De esta manera, las FARC empiezan a apoderarse --desde el punto militar, político y económico-- de los territorios de la Amazonía colombiana. Desde la década de los setenta y ochenta empiezan a ejercer influencia directa en los departamentos de Caquetá, Putumayo y Amazonas, y posteriormente, en los noventa consolidaron estructuras en Guainía y Vaupés, debido al auge de la minería ilegal.

En 1991, luego del proceso constituyente que gestó los nuevos cimientos del Estado colombiano, fueron abolidos los Territorios Nacionales, hasta ese entonces asistidos como si se tratase de sujetos con minoría de edad. Cada una de las intendencias en las que estaba dividido el territorio Amazónico se convirtió en Departamentos, con autonomía administrativa y presupuestal, además de control político local. También se avanzó, igualmente, en materia de diversidad cultural con el reconocimiento de sujetos colectivos a los indígenas, y la protección especial por parte del Estado colombiano por constituir una minoría étnica (Semper, 2006).

No obstante, el cambio experimentado por la región fue brusco. Estos territorios aún conservaban los principios de los antiguos Territorios Nacionales, y habían sido invadidos por el conflicto armado interno y por el narcotráfico. Así, las nuevas entidades territoriales no cambiaron el panorama social ni económico de la región. Solo se redistribuyeron los poderes locales, con amplia influencia de la FARC, desde donde aumentaron sus fuentes de financiación ${ }^{5}$. Así, desde finales de los ochenta y comienzos de los noventa, consolidaron su presencia e

5 En este punto, la Misión de Observación Electoral (MOE), La Corporación Nuevo Arco Iris y el centro de investigación CERAC de la Universidad de los Andes realizaron estudios detallados para los departamentos de Amazonas, Caquetá, Guainía, Guaviare, Putumayo y Vaupés. Allí se pueden observar los vínculos de la estructura política regional con las FARC. 
influencia en la región, y actualmente hacen presencia en la Amazonía colombiana con el Bloque Sur, Frentes 1,15, 16, 32, 48, 49, 52 y 63.

\section{Narcotráfico y acción del Estado colombiano.}

Los cultivos de coca en la Amazonía colombiana se iniciaron en la década de 1980 en los departamentos de Caquetá, Putumayo y Guaviare; y desde un primer momento se constituyeron en una importante fuente de ingresos para los grupos armados ilegales. La consolidación de los precios de la cocaína en los mercados internacionales ${ }^{6}$, especialmente el norteamericano, los amplios márgenes de utilidad del negocio y el control territorial que ejercían las FARC en la zona, convirtieron dicho fenómeno en una verdadera amenaza regional y nacional (Observatorio DESC Amazonía, 2007, p. 50).

La dinámica del narcotráfico para los noventa no cambió, a pesar de los esfuerzos estatales y el nuevo pacto político de 1991, y contrario a lo esperado, en la Amazonía colombiana crecía a grandes pasos ${ }^{7}$, acompañado de la consolidación política, militar y económica de las FARC, quienes en 1998 controlaban casi la totalidad del territorio amazónico (Cadena, 2002). Para enfrentar este flagelo, el gobierno colombiano de Andrés Pastrana, con la ayuda financiera del gobierno de los Estados Unidos, crearon el denominado Plan Colombia, una estrategia coactiva que pretendía convertirse en el principal instrumento para acabar con el narcotráfico en Colombia (Observatorio DESC Amazonía, 2007, pp. 5152) y que ha tenido un costo aproximado de 7.500 millones de dólares. El instrumento utilizado por el Plan Colombia para combatir el narcotráfico ${ }^{8}$ es la aspersión aérea con Glifosato ${ }^{9}$.

6 Con respecto a los precios internacionales de la hoja de coca, la pasta de coca, la base de coca y la cocaína, el programa de Naciones Unidas contra la Droga y el Delito (UNOCD) hace un seguimiento de los precios en el mercado nacional e internacional desde 2005. Para ampliar esta información consultar: ONODC. 2011. Colombia: monitoreo de cultivos de coca 2010. Programa de monitoreo de cultivos ilícitos, Gobierno de Colombia.

7 Según datos de Dirección Nacional de Estupefacientes, los cultivos ilícitos la Amazonía crecieron desde 1990 hasta el año 2000 en un 242\%. Para 1990, entre los departamentos de Guaviare, Caquetá y Putumayo sumaban unas 32.200 hectáreas. Para comienzos de siglo, esta cifra alcanzaba las 110.244 hectáreas.

8 Actualmente, se discute la efectividad de las políticas antidrogas en los países andinos debido a los bajos resultados obtenidos, especialmente porque no ha contribuido a la disminución espacial del cultivo de coca, y no ha frenado la violencia y el conflicto armado que el fenómeno genera en los países andinos y en Centroamérica.

9 Para consultar la ficha técnica del Glifosato se puede acceder al siguiente, que pertenece a la Red de Acción en Plaguicidas y sus Alternativas de América Latina (RAP-AL): http://www.rap-al. org/articulos_files/Glifosato_Enlace_80.pdf 
En materia de salud humana y ambiente son varios los estudios que dan cuenta de los impactos de las fumigaciones con herbicidas que utilizan Glifosato (Nivia, 2000; Monroy, Cortés, Sicard \& Groot, 2005). Se señala la destrucción de especies vegetales, esterilización de suelos en ecosistemas frágiles, toxicidad aguda, muerte numerosa de pecuarios, aves y roedores, y la contaminación de las fuentes hídricas, de tal manera que afecta a las cadenas tróficas y organismos acuáticos, y genera problemas de salud a los pobladores que hacen uso de esas aguas y de los peces contaminados. Asimismo, ocasiona perjuicios graves para los cultivos de pan llevar y pasturas de los campesinos; afectan el bosque tropical, la flora, la fauna y los ecosistemas propios de la biodiversidad.

Con respecto a los principales efectos de la aplicación del Plan Colombia en la Amazonía colombiana se pueden enumerar en los siguientes: i) la fumigación indiscriminada generó nuevas dinámicas de traslado de los cultivos y de la producción de materia prima debido a la dificultad de sustituir los cultivos por la presencia de las FARC en la región y por las pocas fuentes de empleo en el territorio (Jaramillo et al., 1989), lo que presionó nuevos territorios con bosques primarios. ii) Debido a que gran parte de la población rural de la Amazonía obtiene ingresos por el cultivo de coca, (Mackenzie, 2010, pp. 2-3), la utilización de los métodos de aspersión de herbicidas debilitaron la producción extensiva de coca, lo cual ocasionó un incremento del desempleo por el desplazamiento de poblaciones (Mora, 2006). iii) No se ha logrado una real disminución de los cultivos de coca y amapola (ONOCD, 2011), a pesar que es una de las zonas del mundo que más fumigaciones ha recibido con herbicidas que contienen Glifosato.

Actualmente, las FARC siguen ejerciendo una gran influencia en la región amazónica y en sus habitantes, lo que les ha permitido sostener el negocio ilícito, y se constituye igualmente en la principal fuente de ingresos de un gran número de indígenas y colonos de la región, quienes mantienen sus cultivos de hoja de coca (Trujillo, 2011). La base de coca y el proceso de transformación en hidrocloruro de cocaína son comercializados a través de las estructuras de las FARC hacia el interior del país para consumo interno y para exportarla a través de las redes en Brasil y Venezuela; y por la cuenca del pacífico a través de las denominadas Bandas Criminales hacia México (Mackenzie, 2010, p. 3). 
Tabla 2.

Área de cultivo de coca en hectáreas

\begin{tabular}{|c|c|c|c|c|c|c|c|c|c|}
\hline Región & 2004 & $\begin{array}{c}\% \\
\text { Subtotal }\end{array}$ & $\begin{array}{c}\% \\
\text { Total }\end{array}$ & 2005 & $\begin{array}{c}\% \\
\text { Subtotal }\end{array}$ & $\begin{array}{c}\% \\
\text { Total }\end{array}$ & 2006 & $\begin{array}{c}\% \\
\text { Subtotal }\end{array}$ & $\begin{array}{c}\% \\
\text { Total }\end{array}$ \\
\hline $\begin{array}{l}\text { Amazonía- } \\
\text { Vaupés }\end{array}$ & 2.588 & $19,2 \%$ & $3,2 \%$ & 2.320 & $14,3 \%$ & $2,7 \%$ & 1.905 & $10 \%$ & $2,4 \%$ \\
\hline $\begin{array}{l}\text { Caquetá- } \\
\text { Putumayo }\end{array}$ & $\begin{array}{c}10.88 \\
8\end{array}$ & $80,8 \%$ & $13,6 \%$ & 13.951 & $85,7 \%$ & $16,2 \%$ & 17.221 & $90 \%$ & $22,1 \%$ \\
\hline $\begin{array}{c}\text { Subtotal } \\
\text { Amazonia }\end{array}$ & $\begin{array}{c}13.47 \\
6\end{array}$ & $100 \%$ & $16,8 \%$ & 16.271 & $100 \%$ & $18,9 \%$ & 19.126 & $100 \%$ & $24,5 \%$ \\
\hline Total Colombia & & 80.000 & & & 86.000 & & & 78.000 & \\
\hline Región & 2007 & $\begin{array}{c}\% \\
\text { Subtotal }\end{array}$ & $\begin{array}{c}\% \\
\text { Total } \\
\end{array}$ & 2008 & $\begin{array}{c}\% \\
\text { Subtotal }\end{array}$ & $\begin{array}{c}\% \\
\text { Total }\end{array}$ & 2009 & $\begin{array}{c}\% \\
\text { Subtotal }\end{array}$ & $\begin{array}{c}\% \\
\text { Total } \\
\end{array}$ \\
\hline $\begin{array}{l}\text { Amazonía- } \\
\text { Vaupés }\end{array}$ & 1.471 & $6,5 \%$ & $1,5 \%$ & 2.018 & $12,6 \%$ & $2,5 \%$ & 1.166 & $11,4 \%$ & $1,6 \%$ \\
\hline $\begin{array}{l}\text { Caquetá- } \\
\text { Putumayo }\end{array}$ & $\begin{array}{c}21.13 \\
1\end{array}$ & $93,5 \%$ & $21,3 \%$ & 13.961 & $87,4 \%$ & $17,2 \%$ & 9.076 & $88,6 \%$ & $12,4 \%$ \\
\hline $\begin{array}{c}\text { Subtotal } \\
\text { Amazonía }\end{array}$ & $\begin{array}{c}22.60 \\
2\end{array}$ & $100 \%$ & $22,8 \%$ & 15.979 & $100 \%$ & $19,7 \%$ & 10.242 & $100 \%$ & $14,0 \%$ \\
\hline Total Colombia & & 99.000 & & & 81.000 & & & 73.000 & \\
\hline Región & 2012 & $\begin{array}{c}\% \\
\text { Subtotal }\end{array}$ & $\begin{array}{c}\% \\
\text { Total }\end{array}$ & 2010 & $\begin{array}{c}\% \\
\text { Subtotal }\end{array}$ & $\begin{array}{c}\% \\
\text { Total }\end{array}$ & 2011 & $\begin{array}{c}\% \\
\text { Subtotal }\end{array}$ & $\begin{array}{c}\% \\
\text { Total }\end{array}$ \\
\hline $\begin{array}{l}\text { Amazonía- } \\
\text { Vaupés }\end{array}$ & 635 & $6,1 \%$ & $1,3 \%$ & 1.331 & $15,3 \%$ & $2,1 \%$ & 717 & $5,1 \%$ & $1,1 \%$ \\
\hline $\begin{array}{l}\text { Caquetá- } \\
\text { Putumayo }\end{array}$ & 9843 & $93,9 \%$ & $20,5 \%$ & 7.363 & $84,7 \%$ & $11,9 \%$ & 13.278 & $94,9 \%$ & $20,7 \%$ \\
\hline $\begin{array}{c}\text { Subtotal } \\
\text { Amazonía }\end{array}$ & 10478 & $100,0 \%$ & $21,8 \%$ & 8.694 & $100,0 \%$ & $14,0 \%$ & 13.995 & $100 \%$ & $21,9 \%$ \\
\hline Total Colombia & & 48.000 & & & 62.000 & & & 64.000 & \\
\hline
\end{tabular}

Fuente: Elaboración propia. Datos obtenidos del Sistema de monitoreo UNODC (2013).

El comportamiento del cultivo de coca en la región amazónica viene disminuyendo desde el 2007, aunque desde el periodo comparativo 2004-2020 no hay disminución en los territorios cultivados, como bien se señaló anteriormente (véase Tabla 2). Igualmente se observa que mientras en el 2004 el área cultivada en la Amazonía representaba el $16,85 \%$ del total de territorio cultivado, en el 2012 representaba el $21,9 \%$. Este último dato resulta representativo, máxime si se tiene en cuenta que el área total en Colombia disminuyó en el periodo 2004-2012 en $20 \%$, lo que evidencia una estabilidad en el cultivo de coca en la región amazónica, probablemente explicado por la autoridad que aún ejercen las FARC en el territorio, y la falta de alternativas de empleo de la población de la zona. 
A pesar de la dinámica del narcotráfico de la región amazónica se vislumbran dos realidades del cultivo de coca. Los departamentos Caquetá-Putumayo concentran cerca del $95 \%$ del total de cultivo de coca en la región, así como también concentran el $75 \%$ de grupos armados de la Amazonía, lo cual evidencia una correlación entre estas dos actividades ilícitas. Los departamentos de Guainía y Amazonas concentran solo el $5 \%$ y se muestra una disminución en el periodo 2004-2010 del 51\%. Estos últimos departamentos no han sido centros importantes para la siembra de coca.

Si bien existe una disminución de áreas destinadas al cultivo de narcóticos en el último año, no hay razones contundentes que den cuenta de una tendencia a la baja de cultivos de coca en la Amazonía colombiana. Los cultivos ilícitos constituyen uno de los problemas con mayores impactos en materia social, ambiental y económica. Por consiguiente estamos frente a un problema con múltiples causas, de impactos negativos que se multiplican en diversos escenarios nacionales, pero que de todas maneras mantienen y retroalimentan el conflicto armado del país.

De cualquier manera, los impactos del conflicto armado en los ecosistemas amazónicos no resultan claros. Para Ospina (2009), hay una relación positiva entre la conservación de cobertura boscosa y la presencia de las FARC en el departamento del Caquetá. En un análisis espacial e histórico desde 1974, cuando las FARC realizan su primera toma en el municipio de Puerto Rico, Caquetá se evidencia la disminución de la población rural por los desplazamientos forzosos y las migraciones internas causadas por la intensidad del conflicto armado y que de alguna forma produjeron la reducción de la presión sobre el bosque y el aumento de procesos de recuperación de este. Sin embargo, las actividades económicas como el narcotráfico, el tráfico ilegal de especies y la minería criminal impactan negativamente la biodiversidad presente en este territorio por la alteración de los equilibrios de los ecosistemas por deforestación y sustracción de fauna y flora nativa, en muchas ocasiones endémica.

\section{Conclusiones.}

La dinámica poblacional humana en la Amazonía colombiana ha respondido a migraciones marginales que han mantenido a gran parte del territorio fuera del alcance del hombre, pero en los últimos 20 años la participación poblacional de estos territorios, con respecto al total nacional, viene aumentando significativamente, concentrándose en 
zonas rurales, gracias al aprovechamiento de extensas zonas boscosas con acceso a una gran variedad de recursos naturales, el auge cocalero y recientemente el boom minero-energético. Esta situación, sin embargo, también refleja un olvido sistemático sobre el territorio más biodiverso del país.

El Estado colombiano no ha logrado, históricamente, ejercer control soberano sobre la Amazonía, y a pesar de las reformas administrativas generadas en el siglo XX, dichos cambios han sido descontextualizados, sin el involucramiento de los poderes locales y sin transición alguna, situación que ha sido aprovechada por grupos armados ilegales FARC-- para constituir una estructura sólida de ilegalidad en los últimos 30 años, motivados por el negocio del narcotráfico que no parece ceder. Así las cosas, en la Amazonía colombiana persiste un conflicto armado interno que involucra al Bloque Sur de las FARC y al Ejercito Nacional de Colombia, y que desde los últimos 10 años se agudiza por cuenta del Plan Colombia, en el que hay una disputa por el territorio para el mantenimiento del negocio de narcotráfico por parte de las FARC y el aprovechamiento de los recursos naturales no renovables allí presentes por parte de Estado, quien quiere recuperar el espacio y la autoridad que siempre despreció a través de la militarización. En medio de esta disputa se encuentran las comunidades de indígenas, los colonos y los bosques amazónicos que aún permanecen conservados.

Si bien no es clara la dirección del impacto que el poblamiento y el conflicto armado ha generado sobre los ecosistemas que pertenecen a la Amazonía, la persistencia de cultivos ilícitos cada vez más fragmentados para no ser detectados por satélites y las nuevas fuentes de financiación de las FARC con la minería ilegal hacen pensar que la relación equilibrada ser humano-naturaleza que se ha mantenido hasta ahora se romperá en contra de la biodiversidad que aún se conserva.

\section{REFERENCIAS}

ALISOS. (2011). Estudio de la Amazonia Colombiana: Informe sobre los factores de transformación y perspectivas de sostenibilidad. Bogotá D.C. Fundación Alisos, Recuperado de http://www. alisos.net/index.php/es/component/phocadownload/category/1documentos?download=29:Documento-41. 
Broderick, W., Celis, L., Hernández, F., Sanguino, A. y Valencia, L. (2005). El regreso de los rebeldes: de la furia de las armas a los pactos, la crítica y la esperanza. Colombia: Corporación Nuevo Arco Iris. Recuperado de: http://www.universilibros.com/index. php?option=com virtuemart\&view=productdetails\&virtuemart product id $=101 \&$ virtuemart_category id $=77$

Cadena, J. (Enero-Abril, 2004). La geografía y el poder. Territorialización del poder en Colombia -el caso de las FARC - De Marquetalia al Caguán. Estudios Políticos, (1), 153-183. Recuperado de http:// www.journals.unam.mx/index.php/rep/article/view/37612/34176

Cepal y Patrimonio Natural. (2013). Amazonía posible y sostenible. Recuperado de http://www.cepal.org/colombia/noticias/ documentosdetrabajo/2/49742/Amazonia posible y sostenible. $\underline{\mathrm{pdf}}$

Chantré y Herrera, J. (1901). Historia de las misiones de la Compañía de Jesús en el Marañón español 1637-1767. Madrid: Imprenta de A. Avrial. Recuperado de: https://archive.org/details/ historiadelasmis00chan

Echandía, C. (1999). Expansión territorial de la guerrilla colombiana: geografía, economía y violencia. Recuperado de http://economia. uniandes.edu.co/content/download/9299/45754/file/expansion territorial.pdf

Jaramillo, E., Mora, L., y Cubides, F. (1989). Colonización, coca y guerrilla. Colombia: Alianza Editorial Colombiana. Recuperado de: http:// www.mamacoca.org/docs de base/Cifras cuadro mamacoca/ Colonizacion coca y guerrilla Jaramillo Mora_y Cubides UNAL 1986.pdf

Kalmanovitz, S. y López, E. (2000). Instituciones y desarrollo agrícola en Colombia a principios del siglo XX. Recuperado de http://www. banrep.gov.co/docum/ftp/borra197.pdf

Mackenzie, E. (2010). FARC y las Bacrim: un frente común. Recuperado de $\quad$ http://www.gees.org/files/article/22052010151814 Analisis-07814.pdf 
Molano, A. (1980). Amnistía y violencia. Colombia: Centro de Investigación y Educación Popular (CINEP). Recuperado de: http://books. google.co.cr/books/about/Amnist\%C3\%ADa y violencia. html?id=AbgMAAAAYAAJ\&redir esc=y

Molano, A. (1984). FARC, veinte años, de Marquetalia a La Uribe. Colombia: Ediciones Aurora. Recuperado de: http://books. google.co.cr/books/about/FARC veinte_a\%C3\%B10s. html?id=72QYAAAAYAAJ\&redir esc=y

Molano, A. (1987). Selva adentro: Una historia oral de la colonización del Guaviare. Colombia, Bogotá: El Áncora Editores. Recuperado de: http://ancoraeditores.com/?s=selva+adentro

Molano,A.(1994).Trochas y fusiles, Bogotá, Colombia: InstitutodeEstudios Políticos y Relaciones Internacionales (IEPRI), Universidad Nacional de Colombia. Recuperado de: http://books.google.co.cr/ books? id=X2FsAAAAMAAJ\&q=Trochas $+y+$ fusiles + A + +Molano

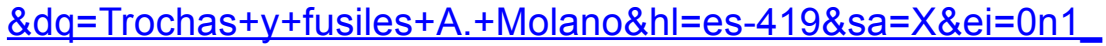
U5bKK-HgsAS5hlHABA\&ved=0CC0Q6AEwAA

Molano, A. (2002). Apaporis: viaje a la última selva. Colombia: Editorial Planeta. Recuperado de: http://books.google. co.cr/books? id=JdFsAAAAMAAJ\&q=Apaporis:+viaje $+a+1 a+\%$ C $3 \%$ BAltima + selva \&dq=Apaporis $:+v i a j e+a+$ la+\%C3\%BAltima+selva\&hl=es $-419 \& \mathrm{sa}=\mathrm{X} \& \mathrm{ei}=\mathrm{mn} 5$ U5fdJYzQsQS23oCgBA\&ved=0CC0Q6AEwAA

Monroy, C; Cortés, A; Sicard, D. \& Groot, H. (2005). Citotoxicidad y genotoxicidad en cédulas expuestas in vitro a glifosato. Biomédica, 25(3), 335-345. Recuperado de: http://www.revistabiomedica. org/index.php/biomedica/article/view/1358

Mora, S. (2006). Amazonía: pasado y presente de un territorio remoto. Colombia, Bogotá: Ediciones Uniandes. Recuperado de: $\quad$ http://books.google.es/books/about/Amazon\%C3\%ADa. html?id=3nQSAQAAIAAJ 
Murad, R. (2003). Estudio sobre la distribución espacial de la población en Colombia. Serie Población y Desarrollo, (48). Recuperado de http://www.eclac.org/publicaciones/xml/0/14000//cl2013-P1.pdf

Nivia, A. (2000). Efectos sobre la salud y el ambiente de herbicidas que contienen glifosato. Recuperado de http://www.glifocidio.org/ docs/impactos\%20generales/ig1.pdf

Observatorio DESC Amazonía. (2007). Situación de los Derechos Económicos Sociales y Culturales. Recuperado de http:// webcache.googleusercontent.com/search?q=cache:http:// judeco.ilsa.org.co:81/node/349

Oficina de las Naciones Unidas contra la Droga y el Delito. (2013). Colombia. Monitoreo de Cultivos de Coca 2012. Junio 2013. Colombia: Oficina de las Naciones Unidas contra la Droga y el Delito y Gobierno de Colombia. Recuperado de http://www.unodc. org/documents/crop-monitoring/Colombia/Colombia_Monitoreo de_Cultivos_de_Coca_2012_web.pdf

Ospina, J. (2009). Relación del conflicto armado y cambio de cobertura de los bosques del alto Caquetá en el periodo 1966-2006. Universidad Nacional de Colombia, Colombia. Recuperado de: $\quad$ http://www.fce.unal.edu.co/index.php?option=com content\&task=view\&id=1275\&Itemid=648\#jorgeo

Pécaut, D. (enero-abril, 1997). Presente, pasado y futuro de la violencia. Análisis Político, (30), Recuperado de http://biblioteca.clacso. edu.ar/ar/libros/colombia/assets/own/analisis30.pdf

Pineda, R. y Alzate, B. (1993). Pasado y presente de Amazonas: su historia económica y social. Colombia: Memorias VI Congreso de Antropología en Colombia, Bogotá, Departamento de Antropología, Universidad de Los Andes. Recuperado de: http:// books.google.co.cr/books/about/Pasado y presente del Amazonas.html?id=PEhsAAAAMAAJ\&redir_esc=y

Rangel, A. (1999). Las FARC-EP: una mirada actual. En Deas, M. y Llorente, M. V. (Eds.). Reconocer la guerra para construir la paz. Bogotá D.C: Editorial Norma. 
Reis, A. (1989). Historia do Amazonas. Belo Horizonte: Editora Itatiaia y Superintendencia do Amazonas.

Semper, F. (2006). Los derechos de los pueblos indígenas de Colombia en la jurisprudencia de la Corte Constitucional. Anuario de Derecho Constitucional Latinoamericano UNAM, Tomo II. Recuperado de http://www.juridicas.unam.mx/publica/librev/rev/dconstla/ cont/2006.2/pr/pr3.pdf

Trujillo, H. (2011). Caracterización socioeconómica de la Amazonía colombiana: desafíos y potencialidades. Manuscrito presentado para su publicación.

Vélez, M. (arzo, 2001). FARC-ELN: evolución y expansión territorial. Desarrollo y Sociedad, (47), 151-225. Recuperado de: http:// economia.uniandes.edu.co/content/download/1234/5740/ file/470cArticulo47_4.pdf 